\title{
ACRF Ingest Software Status: \\ New, Current, and Future
}

Revision 3
A.S. Koontz,
S. Choudhury
B.D. Ermold
K.L. Gaustad

November 2007

Work supported by the U.S. Department of Energy,

Office of Science, Office of Biological and Environmental Research 


\section{DISCLAIMER}

This report was prepared as an account of work sponsored by the U.S. Government. Neither the United States nor an agency thereof, nor any of their employees, makes any warranty, express or implied, or assumes any legal liability or responsibility for the accuracy, completeness, or usefulness of any information, apparatus, product, or process disclosed, or represents that its use would not infringe privately owned rights. Reference herein to any specific commercial product, process, or service by trade name, trademark, manufacturer, or otherwise, does not necessarily constitute or imply its endorsement, recommendation, or favoring by the U.S. Government or any agency thereof. The views and opinions of authors expressed herein do not necessarily state or reflect those of the U.S. Government or any agency thereof. 


\section{Introduction}

The purpose of this report is to provide status of the ingest software used to process instrument data for the Atmospheric Radiation Measurement Program Climate Research Facility (ACRF). The report is divided into 4 sections: (1) for news about ingests currently under development, (2) for current production ingests, (3) for future ingest development plans, and (4) for information on retired ingests. Please note that datastreams beginning in " $\mathrm{xxx}$ " indicate cases where ingests run at multiple ACRF sites, which results in a datastream(s) for each location.

Readers of this status report may want to consult our current list of instrument mentors at http://www.arm.gov/instruments/mentors.php or our list of software developers at http://engineering.arm.gov/engr/task/developercontacts.stm.

Another useful utility is the current datastream status, presented from the ARM Data Management Facility (DMF) perspective, which can be found at http://c1.dmf.arm.gov/ds/dsview/gui/datastream.php.

Hint: Select the "Login as Guest Account" option. Depending on the speed of your internet connection, it may take a few minutes for the complete display to generate. Datastream status for the current calendar month will be displayed. The legend (visible in the upper right hand area) will help you understand the display. In addition, the number (ideally 24.0) indicates the number of hours of data for the day in question.

For those who are interested in the contents of datastreams generated by ARM software, refer to the data object design files at http://science.arm.gov/tool/dod/showdod.php. 


\section{Contents}

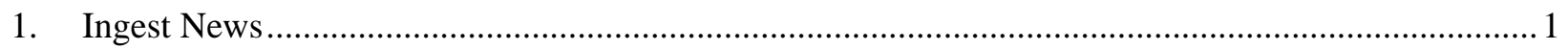

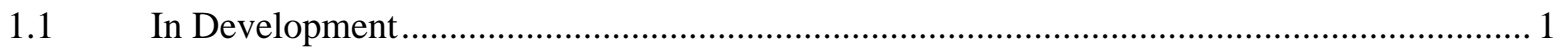

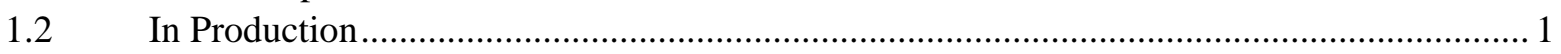

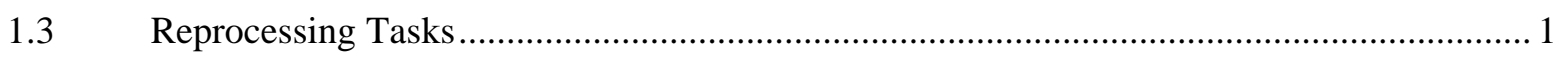

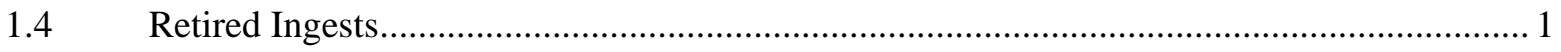

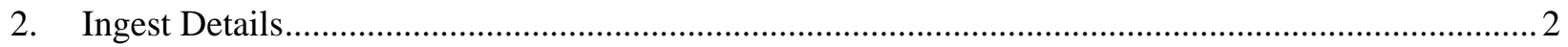

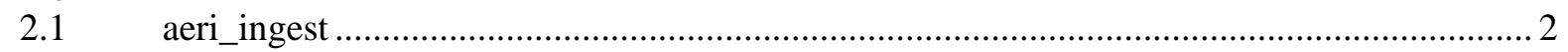

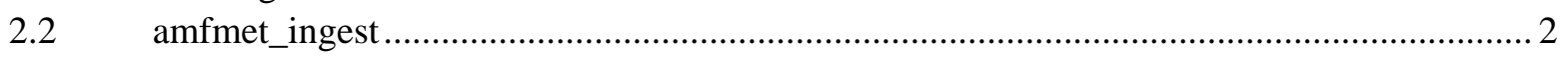

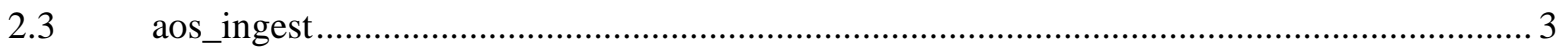

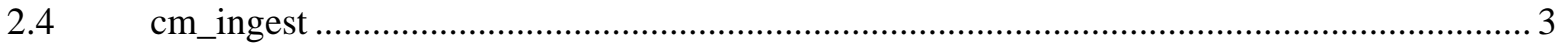

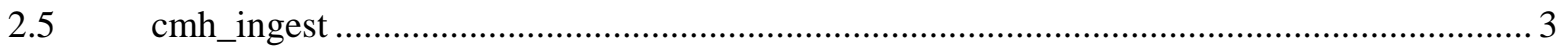

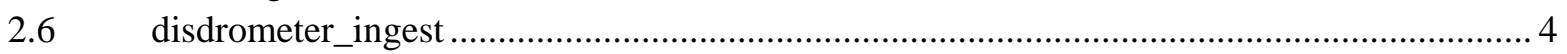

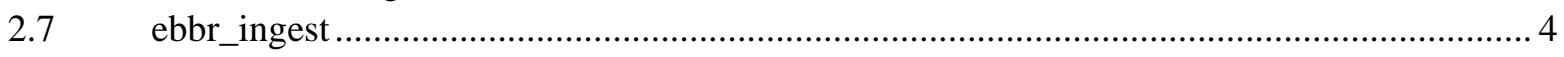

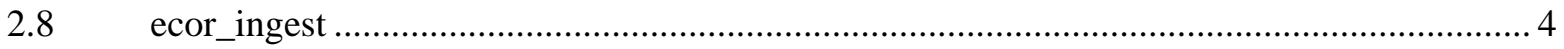

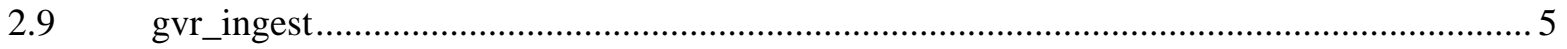

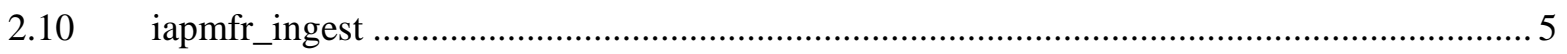

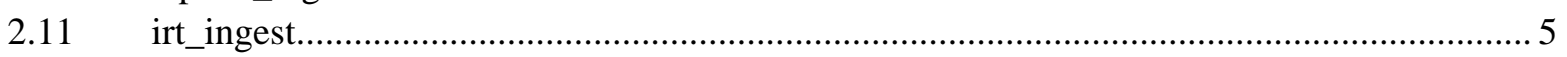

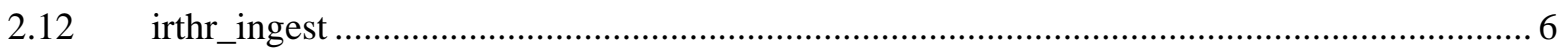

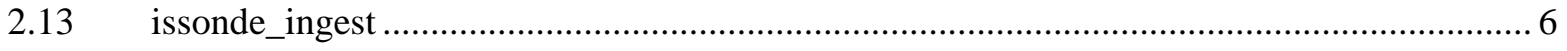

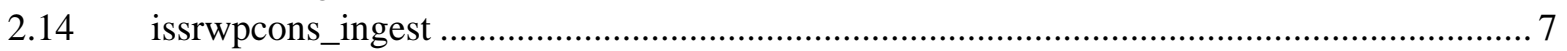

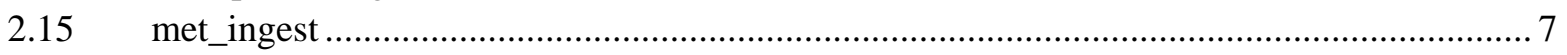

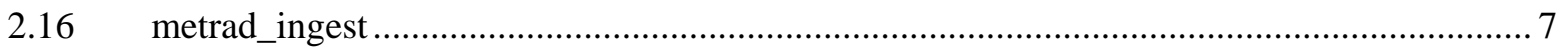

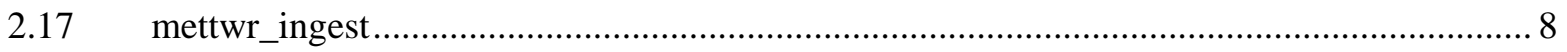

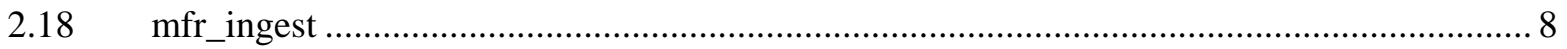

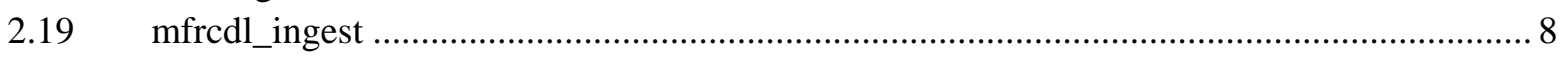

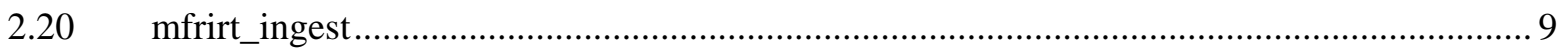

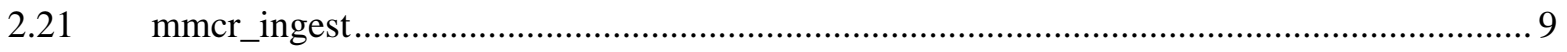

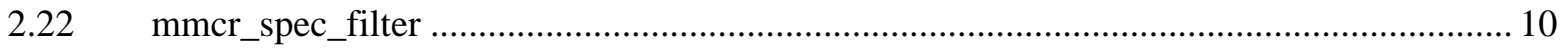

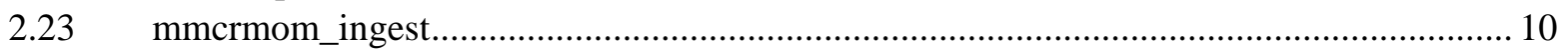

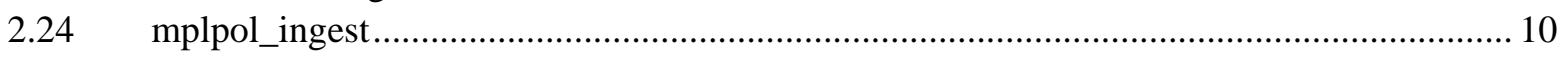

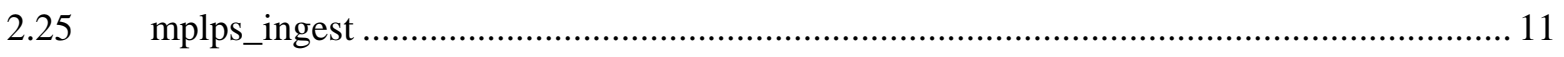

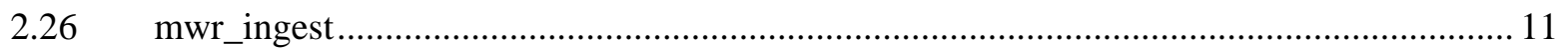

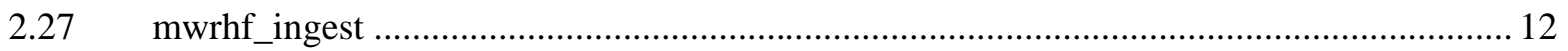

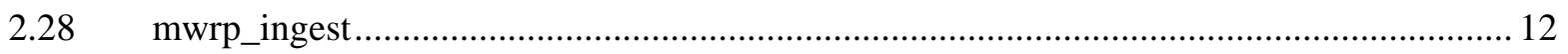

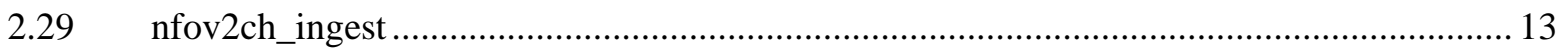

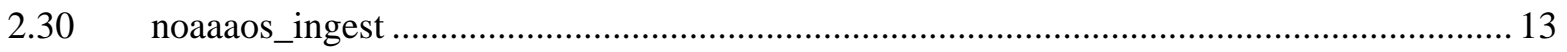

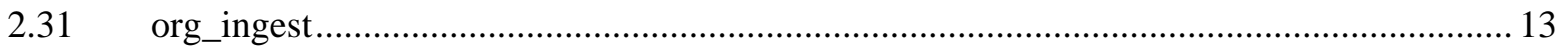

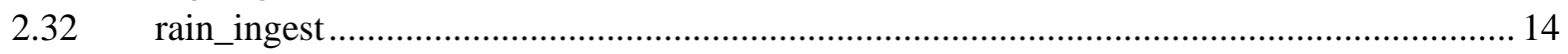

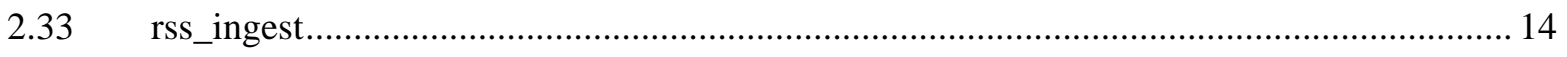

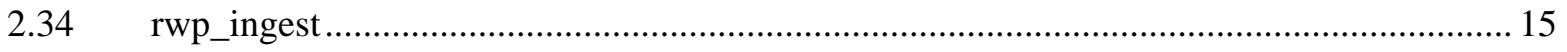

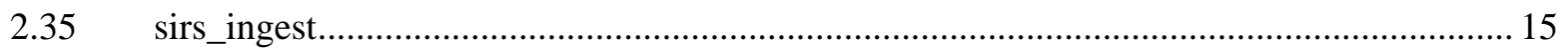

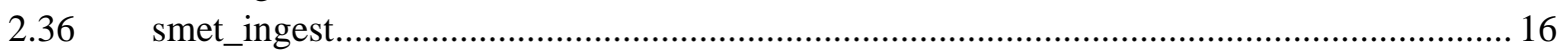

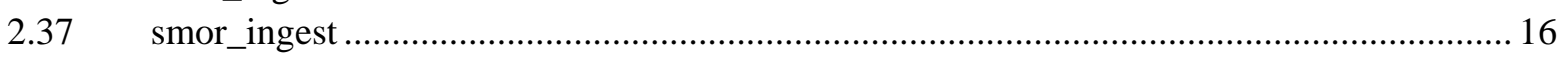




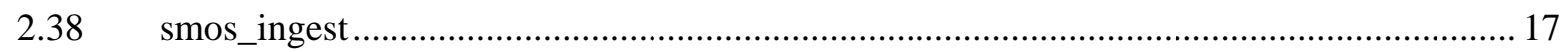

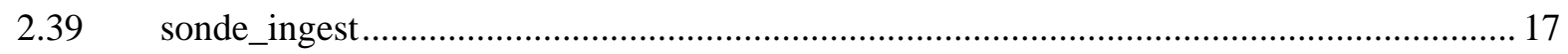

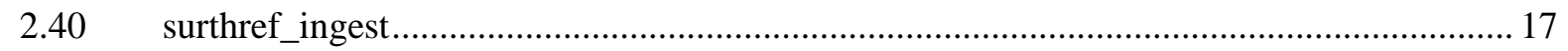

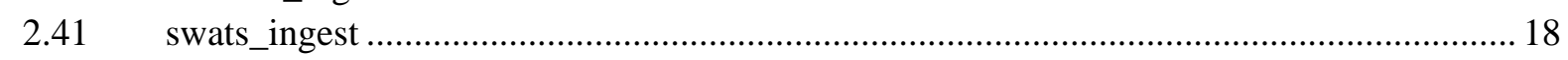

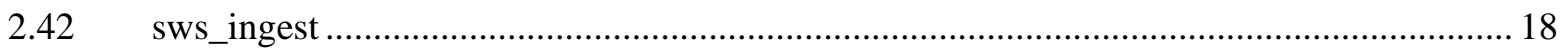

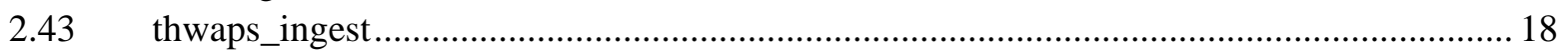

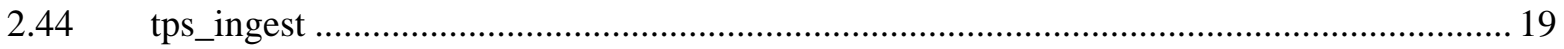

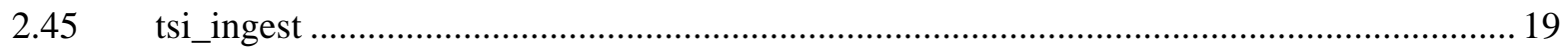

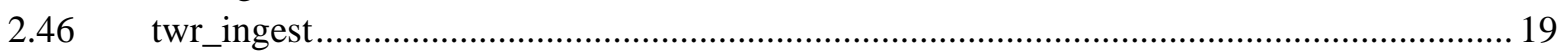

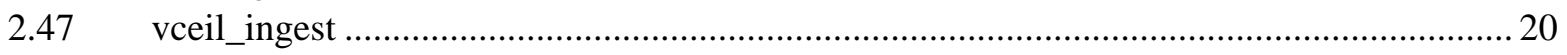

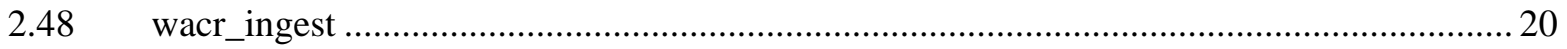

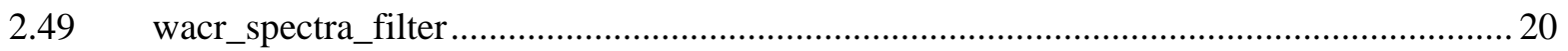

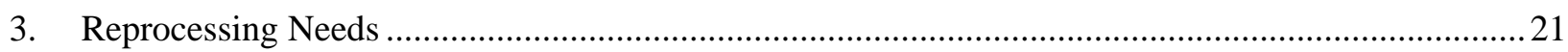

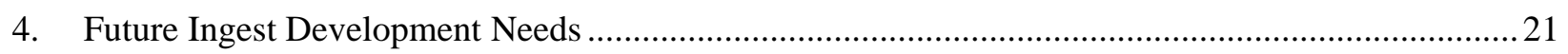




\section{Ingest News}

\section{$1.1 \quad$ In Development}

We are currently working on the following ingests:

iapmfr_ingest

isssonde_ingest

mwrhf ingest

sws_ingest

$\underline{\text { wacr_spectra_filter }}$

\subsection{In Production}

aeri ingest

amfmet ingest

aos_ingest

disdrometer ingest

ebbr ingest

ecor_ingest

gvr ingest

irt ingest

irthr_ingest

met ingest

metrad_ingest

mettwr_ingest

mfrcdl_ingest

$\underline{\text { mfr ingest }}$

mmcrmom_ingest

mmcr_spec_filter

mplpol ingest

mwr_ingest

$\underline{\text { mwrp_ingest }}$
nfov2ch ing
org ingest
rain_ingest
rss ingest
rwp ingest
sirs_ingest
smet ingest
smor ingest
smos_ingest
sonde ingest
surthref ingest
swats_ingest
sws_ingest
thwaps ingest
tps_ingest
tsi_ingest
twr_ingest
vceil_ingest
wacr_ingest

\subsection{Reprocessing Tasks}

A list of active reprocessing tasks and development needs related to reprocessing will be provided in this section.

\section{$1.4 \quad$ Retired Ingests}

This section lists ingest software that has been retired from production.

cm_ingest

cmh_ingest

issrwpcons ingest

isssonde_ingest 
mfrirt_ingest

mmcr_ingest

mplps ingest

noaaaos_ingest

\section{Ingest Details}

In the following sections, we will provide very basic information about the ingest software currently running in production. We list the mentor, lead developer, backup developer, basic information about the processing done by the ingest, and the current operational status. Detailed instrument information can be found at http://www.arm.gov/instruments/.

\section{1 aeri_ingest}

Mentors: $\quad$ Dave Turner and Ralph Dedecker, UWISC

Lead Developer: $\quad$ Brian Ermold, PNNL

Backup Developer: $\quad$ Sutanay Choudhury, PNNL

Current Version: $\quad$ 8.0-0, 2006/10/31

Status: Running

Recent BCRs: $\quad$ 1241, 1212, 1202

\section{Description:}

The aeri_ingest is used to read raw data generated by the Atmospherically Emitted Radiance Interferometer (AERI). The following datastreams are generated:

xxxaerich1Fn.b1, channel 1 data

xxxaerich2Fn.b1, channel 2 data

xxxaeriengineerFn.b1, contains engineering data

xxxaerisummaryFn.b1, summary data

\section{2 amfmet_ingest}

Mentor: $\quad$ Mike Ritsche, ANL

Lead Developer: $\quad$ Sutanay Choudhury, PNNL

Backup Developer: $\quad$ Brian Ermold, PNNL

Current Version: $\quad$ 2.0-0, 2006/09/07

Status: Online

Recent BCRs: 1395

\section{Description:}

Database entries were updated.

The amfmet_ingest is used to read raw data generated by the ARM Mobile Facility (AMF) surface meteorology measurements. The following netCDF (i.e., network common data format) datastream is generated:

xxxmetFn.b1

xxxcmhFn.b1 


\section{3 aos_ingest}

Mentor:

John Ogren, NOAA

Lead Developer:

Annette Koontz, PNNL

Backup Developer:

Brian Ermold, PNNL

Current Version:

9.6-0, 2007/11/19

Status:

Running

Recent BCRs:

1430, 1374, 1293, 1282

\section{Description:}

A new release of the aos_ingest (Baseline Change Request [BCR] 1430) corrects parsing of the missing value codes from the National Oceanic and Atmospheric Administration's (NOAA's) datastream, xxxaosccnFn.a1.

The following datastreams are generated:

xxxaosFn.a1

xxxaosauxFn.a1

xxxaosccnFn.a1

\section{4 cm_ingest}

Mentor: $\quad$ To be determined (TBD)

Lead Developer: $\quad$ TBD

Backup Developer: $\quad$ TBD

Current Version: $\quad$ 7.7-0, 2003/10/09

Status: $\quad$ TBD

\section{Description:}

The cm_ingest processed data collected from chilled mirror instrumentation at the Southern Great Plains (SGP) site. It produced the following datastreams:

xxxcmFn.b1

xxxcm25mFn.b1

xxxcm60mFn.b1

\section{5 cmh_ingest}

$\begin{array}{ll}\text { Mentor: } & \text { TBD } \\ \text { Lead Developer: } & \text { TBD } \\ \text { Backup Developer: } & \text { TBD } \\ \text { Current Version: } & \text { 7.5-0, 2003/05/28 } \\ \text { Status: } & \text { TBD }\end{array}$

\section{Description:}

The cmh_ingest processed data collected from chilled mirror hygrometer instrumentation at the North Slope of Alaska (NSA) Barrow (C1) and Atqasuk (C2) facilities. It produced the following datastreams: 


\section{6 disdrometer_ingest}

Mentor: $\quad$ Mary Jane Bartholomew, BNL

Lead Developer: $\quad$ Sutanay Choudhury, PNNL

Backup Developer: $\quad$ Brian Ermold, PNNL

Current Version: $\quad$ 2.1-0, 2007/04/23

Status: Running

Recent BCRs: $\quad$ 1362, 1346, 1251, 1156

\section{Description:}

This ingest was upgraded to handle large files. The disdrometer_ingest is used to read data from disdrometer instruments. Disdrometers are used to collect data from tipping bucket rain gauges. The following netCDF datastreams are generated:

xxxdisdrometerFn.b1

\section{7 ebbr_ingest}

Mentor:

David Cook, ANL

Lead Developer:

Sutanay Choudhury, PNNL

Backup Developer:

Brian Ermold, PNNL

Current Version:

8.1-0, 2006/09/05

Status:

Running

Recent BCRs:

1036, 674

\section{Description:}

The ebbr_ingest reads data from the Energy Balance Bowen Ratio (EBBR) system. The following datastreams are generated:

xxx5ebbrFn.b1, 5-minute data

xxx15ebbrFn.b1, 15-minute data

xxx30ebbrFn.b1, 30-minute data

\section{8 ecor_ingest}

Mentor:

Lead Developer:

Backup Developer:

Current Version:

Status:

Recent BCRs:
David Cook, ANL

Sutanay Choudhury, PNNL

Brian Ermold, PNNL

8.0, 2006/10/25

Running

1352, 1218, 1151, 1039, 1015

\section{Description:}

The ecor_ingest reads data from the Eddy Correlation Flux Measurement System (ECOR) and generates netCDF datastreams, which provide in situ, half-hour measurements of the surface turbulent fluxes of momentum, sensible heat, latent heat, and carbon dioxide. Datastreams generated include the following: xxx30ecorFn.b1 


\title{
2.9 gvr_ingest
}

\author{
Mentor: $\quad$ Maria Cadeddu, ANL \\ Lead Developer: $\quad$ Annette Koontz, PNNL \\ Backup Developer: $\quad$ Brian Ermold, PNNL \\ Current Version: $\quad$ 1.3-0, 2007/02/20 \\ Status: $\quad$ Running \\ Recent BCRs: $\quad$ 1344, $1338,1329,1287,1255,1189$
}

\section{Description:}

The gvr_ingest reads data generated by the $183.3 \mathrm{GHz}$ radiometer and generates netCDF datastreams. The G-Band Vapor Radiometer (GVR) is located at the NSA C1 site. Datastreams generated include the following:

xxxgvrFn.a0

xxxgvrFn.b1

\subsection{0 iapmfr_ingest}

$\begin{array}{ll}\text { Mentor: } & \text { Gary Hodges, NOAA } \\ \text { Lead Developer: } & \text { Annette Koontz, PNNL } \\ \text { Backup Developer: } & \text { Brian Ermold, PNNL } \\ \text { Version: } & \text { N/A } \\ \text { Status: } & \text { Development } \\ \text { Recent BCRs: } & 1422 \text { - Approved }\end{array}$

\section{Description:}

The datastreams are in final review by the mentor. As soon as the mentor approves the datastream structure, the iapmfr_ingest will be released. In preparation for this release, the zip2tar utility and the preprocess_IAPMFR utility have been released into production. The iapmfr_ingest requires that only the Global Positioning System (GPS) and Mutifilter Radiometer (MFR) data be extracted from the In-situ Aerosol Profiles (IAP) data. This is done via a combination of the zip2tar and preprocess_IAPMFR software to merge the GPS and MFR data into a single file for each flight.

We expect to generate the following datastream names:

sgpiapmfrC1.a0

sgpiapmfrC1.b1

\subsection{1 irt_ingest}

Mentor:

Lead Developer:

Backup Developer:

Current Version:

Status:

Recent BCRs:
Victor Morris, PNNL

Brian Ermold, PNNL

Sutanay Choudhury, PNNL

9.2-0, 2006/10/27

Running

1384, 988, 890, 777, 668 


\section{Description:}

The irt_ingest, similar to the irthr_ingest, reads data from the Infrared Thermometer (IRT) instruments. However, this ingest is designed for the older IRTs that report data every 20 seconds. There is one IRT located on a tower at 10 meters above the ground and another at 25 meters above the ground. The towermounted instruments are pointed downward. Datastreams generated include the following:

xxxirt10mFn.b1, 10-meter tower data xxxirt25m20sFn.a0. 25-meter tower data, 20-second interval xxxirt25mFn.b1, 25-meter tower data, 1-minute averages

\subsection{2 irthr_ingest}

$\begin{array}{ll}\text { Mentor: } & \text { Victor Morris, PNNL } \\ \text { Lead Developer: } & \text { Sutanay Choudhury, PNNL } \\ \text { Backup Developer: } & \text { Brian Ermold, PNNL } \\ \text { Current Version: } & 2.0-0,2006 / 08 / 14 \\ \text { Status: } & \text { Running } \\ \text { Recent BCRs: } & 1111\end{array}$

\section{Description:}

The irthr_ingest reads data from the high-resolution Infrared Thermometer (IRT) instruments distributed around the SGP. Datastreams generated are for 200-millisecond, 2-seconds, and 1-minute sample intervals and include the following:

xxxirt200msFn.a1, 200-millisecond data

xxxirt2sFn.b1, 2-second data

xxxirtFn.b1, 1-minute data

\subsection{3 issonde_ingest}

$\begin{array}{ll}\text { Mentor: } & \text { Barry Lesht, ANL } \\ \text { Lead Developer: } & \text { Brian Ermold, PNNL } \\ \text { Backup Developer: } & \text { TBD } \\ \text { Version: } & 8.0-0,2007 / 03 / 20 \\ \text { Status: } & \text { Retired ingest being revised for historical data processing } \\ \text { Recent BCRs: } & 1337\end{array}$

\section{Description:}

The isssonde_ingest was used to process sonde data in the past. It is being revised for use with the new databases for the purpose of reprocessing historical data and will result in the following datastreams:

xxxisssonde10sFn.a1

xxxisssondeFn.a1 


\subsection{4 issrwpcons_ingest}

$\begin{array}{ll}\text { Mentor: } & \text { TBD } \\ \text { Lead Developer: } & \text { TBD } \\ \text { Backup Developer: } & \text { TBD } \\ \text { Current Version: } & \text { 7.1-0, 2001/02/23 } \\ \text { Status: } & \text { TBD }\end{array}$

\section{Description:}

The issrwpcons_ingest was used to process data from an external rass wind profiler (RWP) located at the Tropical Western Pacific (TWP). It produced the following datastreams:

xxx915issrwptempconFn.a1

xxx925issrwpwindconFn.a1

\subsection{5 met_ingest}

Mentor: $\quad$ Mike Ritsche, ANL

Lead Developer: $\quad$ Sutanay Choudhury, PNNL

Backup Developer: $\quad$ Brian Ermold, PNNL

Current Version: $\quad$ 7.8-0, 2001/10/20

Status: $\quad$ Running

Recent BCRs: $\quad$ 1335, 1232, 1163, 1059

\section{Description:}

The met_ingest processed data collected from conventional in situ sensors measuring meteorological data such as wind speed, barometric pressure, and so on. The following datastream is generated:

xxxmetFn.b1

\subsection{6 metrad_ingest}

Mentor:

Mike Ritsche, ANL

Lead Developer:

Backup Developer:

Current Version:

Status:

Recent BCRs:
Sutanay Choudhury, PNNL

Brian Ermold, PNNL

2.0-0, 2006/10/31

Offline

None.

\section{Description:}

The metrad_ingest processes raw radiometer and meteorological data to produce NetCDF files. The following datastreams are generated:

nimmetS1.b1

nimradS1.b1 


\subsection{7 mettwr_ingest}

Mentor:

Lead Developer:

Backup Developer:

Current Version:

Status:

Recent BCRs:
Mike Ritsche, ANL

Brian Ermold, PNNL

Sutanay Choudhury, PNNL

2.1-0, 2006/09/08

Running

1133

\section{Description:}

The mettwr_ingest processes data collected from conventional in situ sensors on the ground and on a tower at 10 meters and 40 meters above the ground. The sensors measure meteorological data such as wind speed, barometric pressure, and so on. The mettwr_ingest is used to process data collected at the NSA from surface and tower meteorological instrumentation. Datastreams generated include the following:

xxxmettwr2hFn.b1

xxxmettwr4hFn.b1

xxxmettwrFn.b1

\subsection{8 mfr_ingest}

Mentor:

Lead Developer:

Backup Developer:

Current Version:

Status:

Recent BCRs:

\author{
Gary Hodges, NOAA \\ Annette Koontz, PNNL \\ Brian Ermold, PNNL \\ 7.19-0, 2006/09/18 \\ Running \\ 1297, 1177, 1145
}

\section{Description:}

Soon data from the Normal Incidence Multifilter Radiometer (NIMFR) will be processed via mfrcdl_ingest. The mfr_ingest is used to process NIMFR, MFR10m, and MFR25m data. The datastreams generated include the following:

xxxmfr10mFn.a0

xxxmfr10mFn.b1

xxxmfr25mFn.a0

xxxmfr25mFn.b1

xxxnimfrFn.a0

xxxnimfrFn.b1

\subsection{9 mfrcdl_ingest}

Mentor:

Lead Developer:

Gary Hodges, NOAA

Backup Developer:

Annette Koontz, PNNL

Current Version:

Brian Ermold, PNNL

Status:

9.9-0, 2007/10/08

Running 
Recent BCRs:

1380,1230

\section{Description:}

Most recently, changes made to the Multifilter Rotating Shadowband Radiometer (MFRSR) processing logic were retracted. Those changes marked data as "missing" that are basically non-physical. However, those changes caused difficulties for the Data Quality Office software, so they were retracted. Logic to handle the non-physical MFRSR data will eventually be handled via a value-added product (VAP).

The following datastreams are generated:

xxxmfrsrFn.a0

xxxmfrsrFn.b1, processed data

xxxmfrsrauxFn.a0

Several SGP MFRSRs have been converted to the Campbell Data Logger. Raw data are being collected. We can now process NIMFR data via this ingest.

\subsection{0 mfrirt_ingest}

$\begin{array}{ll}\text { Mentor: } & \text { N/A } \\ \text { Lead Developer: } & \text { Annette Koontz, PNNL } \\ \text { Backup Developer: } & \text { N/A } \\ \text { Current Version: } & \text { 8.1-0, 2006/03/06 } \\ \text { Status: } & \text { Offline }\end{array}$

\section{Description:}

The mfrirt_ingest was used to process data collected from an IRT instrument that was included in an MFR datastream at SGP C1. It produced the following datastreams:

xxxmfrirt10mFn.b1

xxxmfrirt25mFn.b1

NOTE: These data have all been reprocessed and cloned to look like sgpirt10mC1.b1 and sgpirt25mC1.b1 data.

\subsection{1 mmcr_ingest}

$\begin{array}{ll}\text { Mentor: } & \text { N/A } \\ \text { Lead Developer: } & \text { Annette Koontz, PNNL } \\ \text { Backup Developer: } & \text { N/A } \\ \text { Current Version: } & 8.0-0,2006 / 11 / 01 \\ \text { Status: } & \text { Retired, replaced by mmcrmom_ingest }\end{array}$

\section{Description:}

The mmcr_ingest has been replaced by the mmcrmom_ingest. The mmcr_ingest was used to process data collected from the first generation of Millimeter Wavelength Cloud Radar (MMCR) instruments. It produced the following datastreams: 
xxxmmcrcalFn.a1

xxxmmcrmomentsFn.a1

xxxmmcrmonFn.a1

\subsection{2 mmcr_spec_filter}

$\begin{array}{ll}\text { Mentor: } & \text { Karen Johnson, BNL } \\ \text { Lead Developer: } & \text { Annette Koontz, PNNL } \\ \text { Backup Developer: } & \text { Brian Ermold, PNNL } \\ \text { Version: } & 2.8-0,2007 / 10 / 22 \\ \text { Status: } & \text { Online at SGP C1 } \\ \text { Recent BCRs: } & 1374\end{array}$

\section{Description:}

Recent changes were implemented to get the filtered data flowing. Currently, this is happening for SGP C1 data only, with filtered spectra data delivered directly to the ARM Archive. The mentor may be providing logic adjustments to better handle thin clouds in the future.

\subsection{3 mmcrmom_ingest}

Mentor: $\quad$ Kevin Widener, PNNL, and Karen Johnson, BNL

Lead Developer: $\quad$ Annette Koontz, PNNL

Backup Developer: $\quad$ Brian Ermold, PNNL

Current Version: $\quad$ 8.5-1, 2007/06/6

Status: Running

Recent BCRs: $\quad$ 1382, 1203, 918, 899

\section{Description:}

The mmcrmom_ingest has been modified recently to better filter out not-a-number and infinity values. The mmcrmom_ingest is used to process data from the MMCR. Datastreams generated include the following:

\section{xxxmmcrmomFn.b1}

Per Engineering Change Order (ECO) 610, the raw and processed MMCR data will be undergoing another facelift. There is no news on when this will happen, but the Engineering Change Request (ECR) was approved.

\subsection{4 mplpol_ingest}

$\begin{array}{ll}\text { Mentor: } & \text { Richard Coulter, ANL } \\ \text { Lead Developer: } & \text { Annette Koontz, PNNL } \\ \text { Backup Developer: } & \text { Brian Ermold, PNNL } \\ \text { Current Version: } & 9.2-0,2007 / 07 / 20 \\ \text { Status: } & \text { Running } \\ \text { Recent BCRs: } & 1392,1315,1233\end{array}$




\section{Description:}

The mplpol_ingest processes data from the Micropulse Lidar (MPL). Datastreams generated include the following:

xxxmplpolFn.b1

Since these data are used by several important “downstream” VAPs, a VAP to average the MPLPOL data has been released and is being run on the DMF. The corresponding averaged datastream names are the following:

xxxmplpolavgFn.c1

xxxmplpolavgFn.s1

The mplpol_ingest is being modified to handle odd data collected at the TWP site in Darwin, Australia, recently.

\subsection{5 mplps_ingest}

$\begin{array}{ll}\text { Mentor: } & \text { Richard Coulter, ANL } \\ \text { Lead Developer: } & \text { Annette Koontz, PNNL } \\ \text { Backup Developer: } & \text { Brian Ermold, PNNL } \\ \text { Current Version: } & \text { 8.0-0, 2006/10/27 } \\ \text { Status: } & \text { Retired }\end{array}$

The mplps_ingest was used to process data collected from a prototype, a polarizing MPL, located at the NSA C1. It produced the following datastream:

xxxmplpsFn.a0

These data were subsequently used as input to the mplavg process, which produced

xxxmplFn.a1

which was used as input to the Active Remotely-Sensed Cloud Locations (ARSCL) VAP. This ingest was retired when the mplpol_ingest was put in production at the NSA C1.

\subsection{6 mwr_ingest}

Mentor: $\quad$ Maria Cadeddu, ANL

Lead Developer: $\quad$ Annette Koontz, PNNL

Backup Developer: $\quad$ Brian Ermold, PNNL

Current Version: $\quad$ 10.0-0, 2007/06/26

Status: Running

Recent BCRs: $\quad$ 1385, 1223 


\section{Description:}

The mwr_ingest processes data from the Microwave Radiometer (MWR). Datastreams generated include the following:

xxxmwrlosFn.b1, line-of-sight data

xxxmwrlosFn.a1, TIP data

The format of the MWRTIP files changed as a result of BCR 1385. The data are being reprocessed so that the MWRTIP files will have a consistent format.

\subsection{7 mwrhf_ingest}

$\begin{array}{ll}\text { Mentor: } & \text { Maria Cadeddu, ANL } \\ \text { Lead Developer: } & \text { Sutanay Choudhury, PNNL } \\ \text { Backup Developer: } & \text { Brian Ermold, PNNL } \\ \text { Version: } & 1.1-0,2007 / 06 / 25 \\ \text { Status: } & \text { Offline } \\ \text { Recent BCRs: } & 1358,1319,1302\end{array}$

\section{Description:}

The mwrhf_ingest processes 90/150-GHz Microwave Radiometer - high frequency (MWRHF) data. This instrument has been installed at the SGP C1 and at the AMF deployment in Germany (FKB M1).

The ingest is being modified to make the file handling logic more robust (EWO 12253).

The following datastreams are generated:

xxxmwrhfFn.b1

\subsection{8 mwrp_ingest}

$\begin{array}{ll}\text { Mentor: } & \text { Maria Cadeddu, ANL } \\ \text { Lead Developer: } & \text { Annette Koontz, PNNL } \\ \text { Backup Developer: } & \text { Sutanay Choudhury, PNNL } \\ \text { Current Version: } & \text { 8.3-0, 2007/09/06 } \\ \text { Status: } & \text { Running } \\ \text { Recent BCRs: } & 1320,1314,1250,1249,1234\end{array}$

\section{Description:}

Recent changes were made to remove not-a-number and infinity values. The mwrp_ingest processes data collected from the Microwave Radiometer Profiler (MWRP). Datastreams generated include the following:

xxxmwrpFn.b1 


\subsection{9 nfov2ch_ingest}

$\begin{array}{ll}\text { Mentor: } & \text { Gary Hodges, NOAA } \\ \text { Lead Developer: } & \text { Sutanay Choudhury, PNNL } \\ \text { Backup Developer: } & \text { TBD } \\ \text { Current Version: } & 11.0-1,2007 / 05 / 01 \\ \text { Status: } & \text { Running } \\ \text { Recent BCRs: } & 1286,1028,1006 \\ & \\ \text { Description: } & \end{array}$

This ingest has been ported to the new database and is currently running for AMF deployment in Germany. The nfov2ch_ingest processes data collected from the Narrow Field of View, 2-channel radiometer (NFOV2).

The following datastream is generated:

xxxnfov2chFn.b1

The mentor indicates that the instrument is out for calibration and/or repair. No estimate is available at this time for its return to production. Also, the nfov2ch_ingest is being modified to use new databases and a new version will be released prior to the AMF deployment in Germany.

\subsection{0 noaaaos_ingest}

Mentor:

John Ogren, NOAA

Lead Developer:

Annette Koontz, PNNL

Backup Developer:

N/A

Current Version:

2.2-0, 2006/12/22

Recent BCRs:

1374

Status:

Retired, became aos_ingest

\section{Description:}

The noaaaos_ingest processed raw (not mentor reviewed) data collected from the NSA and the AMF AOS instruments. It produced the following datastreams:

xxxaosFn.a0

xxxaosauxFn.a0

xxxaosccnFn.a0

\subsection{1 org_ingest}

Mentor:

Lead Developer:

Backup Developer:

Current Version:

Status:
Michael Ritsche, ANL

Sutanay Choudhury, PNNL

Brian Ermold, PNNL

1.0-0 1007/10/25

Released, Instrument 
Recent BCRs:

1389

\section{Description:}

The org_ingest processes optical rain gauge measurements. The first version of the org_ingest has been released into production.

Datastreams generated include the following:

xxxorgFn.b1

\subsection{2 rain_ingest}

Mentor:

Lead Developer:

Backup Developer:

Current Version:

Status:

Recent BCRs:
Mary Jane Bartholomew, BNL Sutanay Choudhury, PNNL Brian Ermold, PNNL

3.0-1, 2007/11/09

Running

1395, 1156

\section{Description:}

The rain_ingest processes tipping bucket measurements. The rain ingest was upgraded to implement a new interpolation algorithm and support a new optical rain gauge instrument (EWO 12168). The upgraded version was released to production.

Datastreams generated include the following:

xxxrainFn.b1

\subsection{3 rss_ingest}

Mentor: $\quad$ Piotr Kiedron, NOAA

Lead Developer: $\quad$ Brian Ermold, PNNL

Backup Developer: $\quad$ Sutanay Choudhury, PNNL

Current Version: $\quad$ 2.0-0, 2006/10/31

Status: $\quad$ Running

Recent BCRs: $\quad$ 1143, 1104

\section{Description:}

The rss_ingest is used to process data collected from Rotating Shadowband Spectroradiometer (RSS) instruments. The datastreams generated include the following:

xxxrssFn.b1

NOTE: Data are processed every couple of months, when the required inputs arrive. 


\subsection{4 rwp_ingest}

Mentor:

Lead Developer:

Backup Developer:

Current Version:

Status:

Recent BCRs:
Richard Coulter, ANL

Brian Ermold, PNNL

Sutanay Choudhury, PNNL

8.1-0, 2007/4/11

Running

1353, 1246, 1186, 974

\section{Description:}

The rwp_ingest processes data collected from Radar Wind Profilers (RWPs). The datastreams generated include the following:

xxx50rwptempFn.a2

xxx50rwptempconFn.a1

xxx50rwptempmomFn.a0

xxx50rwptempspecFn.a0

xxx50rwpwindconFn.a1

xxx50rwpwindmomFn.a0

xxx50rwpwindspecFn.a0

xxx915rwptempFn.a2

xxx915rwptempconFn.a1

xxx915rwptempmomFn.a0

xxx915rwptempspecFn.a0

xxx915rwpwindconFn.a1

xxx915rwpwindmomFn.a0

xxx915rwpwindspecFn.a0

xxx1290rwpwindconFn.a1

xxx1290rwpwindmomFn.a0

xxx1290rwpwindspecFn.a0

For the next AMF installation, the rwp_ingest will require modification to handle the new configuration of RWP data.

\subsection{5 sirs_ingest}

Mentor:

Lead Developer:

Backup Developer:

Current Version:

Status:

Recent BCRs:
Tom Stoffel, NREL

Brian Ermold, PNNL

Sutanay Choudhury, PNNL

10.0-0, 2006/08/31

Running

1080, 1040

\section{Description:}

The sirs_ingest processes data collected from Solar Infrared Radiation Station (SIRS) instruments.

Datastreams generated include the following:

xxxsirsFn.b1 
xxxsirs20sFn.a0

xxxskyrad60sFn.b1

xxxskyrad20sFn.a0

xxxgndrad60sFn.b1

xxxgndrad20sFn.a0

\subsection{6 smet_ingest}

Mentor:

Lead Developer:

Backup Developer:

Current Version:

Status:

Recent BCRs:
Michael Ritsche, ANL

Brian Ermold, PNNL

Sutanay Choudhury, PNNL

8.1-0, 2006/10/04

Running

1213, 1048, 738

\section{Description:}

The smet_ingest processes data collected from Surface Meteorological Instruments for TWP (SMET). Datastreams generated include the following:

xxxsmet60sFn.b1

\subsection{7 smor_ingest}

Mentor:

Lead Developer:

Backup Developer:

Version:

Status:

Recent BCRs:
TBD

Brian Ermold, PNNL

Annette Koontz, PNNL

7.11-0, 2003/10/09

Retired ingest being revised for reprocessing historical data from Sky Radiometers on Stand for Downwelling Radiation (SKYRAD) and Ground Radiometers on Stand for Upwelling Radiation (GNDRAD)

\section{Description:}

This ingest has been taken out of retirement. It will be used for reprocessing of historical SKYRAD, GNDRAD, and SMET data, but with the addition of logic to use new databases to improve performance and to generate new datastreams comparable to those currently being generated by the sirs_ingest. This reprocessing is needed, at least in part, for subsequent processing by one or more VAPs.

The following datastreams will be generated:

xxxskyrad20sFn.a0

xxxskyrad60sFn.b1

xxxgndrad20sFn.a0

xxxgndrad60sFn.b1

xxxsmet60sFn.b1 


\subsection{8 smos_ingest}

Mentor: $\quad$ Michael Ritsche, ANL

Lead Developer: $\quad$ Brian Ermold, PNNL

Backup Developer: $\quad$ Sutanay Choudhury, PNNL

Current Version: $\quad$ 8.1-1, 2007/03/14

Status: $\quad$ Running

Recent BCRs: $\quad$ 1298, 1257,1178

\section{Description:}

The smos_ingest processes data from the Surface Meteorological Observation System (SMOS) instruments. The smos_ingest has been updated to handle changes being made to the sensors. It is being updated to add new calibration variables (EWO-11989). Modifications to the datastreams are underway to remove snow-depth measurements. Datastreams generated include the following:

xxx1smosFn.b1

xxx30smosFn.b1

\subsection{9 sonde_ingest}

$\begin{array}{ll}\text { Mentor: } & \text { Barry Lesht, ANL } \\ \text { Lead Developer: } & \text { Annette Koontz, PNNL } \\ \text { Backup Developer: } & \text { Brian Ermold, PNNL } \\ \text { Current Version: } & 8.1-0,2006 / 09 / 28 \\ \text { Status: } & \text { Running } \\ \text { Recent BCRs: } & 1245,1229\end{array}$

\section{Description:}

The sonde_ingest processes data collected from Balloon-Borne Sounding System (sonde). Datastreams generated include the following:

xxxsondewnpnFn.b1

\subsection{0 surthref_ingest}

$\begin{array}{ll}\text { Mentor: } & \text { Michael Ritsche, ANL } \\ \text { Lead Developer: } & \text { Sutanay Choudhury, PNNL } \\ \text { Backup Developer: } & \text { Brian Ermold, PNNL } \\ \text { Current Version: } & 2.0-0,2006 / 11 / 01 \\ \text { Status: } & \text { Running } \\ \text { Recent BCRs: } & 1124,1106\end{array}$

\section{Description:}

The surthref_ingest processes data collected from Surface Temperature and Humidity Reference (SURTHREF) system instruments. Datastreams generated include the following:

xxxsurthrefFn.b1 


\title{
2.41 swats_ingest
}

Mentor:

Lead Developer:

Backup Developer:

Current Version:

Status:

Recent BCRs:
John Harris, CIMMS

Brian Ermold, PNNL

Sutanay Choudhury, PNNL

10.0-0, 2006/09/07

Running

1017,896

\section{Description:}

The swats_ingest processes data collected from the Soil Water and Temperature System (SWATS).

Datastreams generated include the following:

xxxswatsFn.b1

xxxswatsspcpFn.b1

\subsection{2 sws_ingest}

\author{
Mentor: \\ Alan Scott Kittelman, CU-Boulder \\ Lead Developer: \\ Sutanay Choudhury, PNNL \\ Backup Developer: \\ Brian Ermold, PNNL \\ Current Version: \\ 3.0-0, 2007/03/06 \\ Status: \\ Running \\ Recent BCRs: \\ 1406, 1347, 1288, 1216

\section{Description:}

The sws_ingest is being modified to handle new calibration logic. More enhancements are expected in November 2007. The sws_ingest processes data collected from the Shortwave Spectroradiometer (SWS). Datastreams generated include the following:

xxxswsFn.b1

xxxswsauxFn.b1

\subsection{3 thwaps_ingest}

$\begin{array}{ll}\text { Mentor: } & \text { Michael Ritsche, ANL } \\ \text { Lead Developer: } & \text { Brian Ermold, PNNL } \\ \text { Backup Developer: } & \text { Sutanay Choudhury, PNNL } \\ \text { Current Version: } & \text { 8.0-0, 2006/08/14 } \\ \text { Status: } & \text { Running } \\ \text { Recent BCRs: } & 726\end{array}$

\section{Description:}

The thwaps_ingest processes data collected from Temperature, Humidity, Wind and Pressure Sensors (THWAPS) instruments. Datastreams generated include the following:

xxxthwapsFn.b1 


\subsection{4 tps_ingest}

$\begin{array}{ll}\text { Mentor: } & \text { Mark Ivey, SNL } \\ \text { Lead Developer: } & \text { Sutanay Choudhury, PNNL } \\ \text { Backup Developer: } & \text { Brian Ermold, PNNL } \\ \text { Version: } & 1.0-0,2006 / 12 / 22 \\ \text { Status: } & \text { Running } \\ \text { Recent BCRs: } & 1387,1366\end{array}$

\section{Description:}

The Total Precipitation Sensor (TPS) will be deployed at both NSA sites in Barrow and Atqasuk soon. The tps_ingest will process data from the Total Precipitation Sensor (precipitation rate and daily accumulated precipitation).

xxxtpsFn.b1

\subsection{5 tsi_ingest}

Mentor: $\quad$ Victor Morris, PNNL

Lead Developer: $\quad$ Sutanay Choudhury, PNNL

Backup Developer: $\quad$ Brian Ermold, PNNL

Current Version: $\quad$ 10.1-0, 2006/11/07

Status: $\quad$ Running

Recent BCRs: $\quad$ 1294, 1247, 1206, 1107

\section{Description:}

The tsi_ingest processes data collected from the Total Sky Imager (TSI). Datastreams generated include the following:

xxxtsicldmaskFn.a1

xxxtsimovieFn.a

xxxtsiskycoverFn.b1

xxxtsiskyimageFn.a1

\subsection{6 twr_ingest}

$\begin{array}{ll}\text { Mentor: } & \text { David Cook, ANL } \\ \text { Lead Developer: } & \text { Brian Ermold, PNNL } \\ \text { Backup Developer: } & \text { Sutanay Choudhury, PNNL } \\ \text { Current Version: } & 8.0-0,2006 / 09 / 07 \\ \text { Status: } & \text { Running } \\ \text { Recent BCRs: } & 727\end{array}$

\section{Description:}

The twr_ingest processes data collected from meteorological instruments located on towers above the ground. The datastreams generated include the following

xxx1440twr21xFn.b1 
xxx1440twr25mFn.b1

xxx1440twr60mFn.b1

xxx1twr10xFn.b1

xxx1twr25mFn.b1

xxx1twr60mC1.b1

xxx30twr10xFn.b1

xxx30twr25mFn.b1

xxx30twr60mFn.b1

\subsection{7 vceil_ingest}

$\begin{array}{ll}\text { Mentor: } & \text { Victor Morris, PNNL } \\ \text { Lead Developer: } & \text { Brian Ermold, PNNL } \\ \text { Backup Developer: } & \text { Annette Koontz, PNNL } \\ \text { Current Version: } & 8.1-0,2006 / 09 / 08 \\ \text { Status: } & \text { Running } \\ \text { Recent BCRs: } & 1295,1132\end{array}$

\section{Description:}

The vceil_ingest processes data collected from Vaisala Ceilometers (VCEILs). Datastreams generated include the following:

xxxvceil25kFn.b1

\subsection{8 wacr_ingest}

Mentor: $\quad$ Kevin Widener, PNNL

Lead Developer: $\quad$ Annette Koontz, PNNL

Backup Developer: $\quad$ Brian Ermold, PNNL

Current Version: $\quad$ 8.1-0, 2006/09/11

Status: Running

Recent BCRs: $\quad$ 1357, 1263, 1242

\section{Description:}

The wacr_ingest processes data collected from W-Band (95 GHz) ARM Cloud Radar (WACR) instruments. Datastreams generated include the following:

xxxwacrFn.b1

\subsection{9 wacr_spectra_filter}

Mentor: Karen Johnson, BNL

Lead Developer: $\quad$ Annette Koontz, PNNL

Backup Developer: $\quad$ Brian Ermold, PNNL

Version: $\quad 3.1-0,2007 / 04 / 12$

Status: Installed

Recent BCRs: $\quad 1349$ 


\section{Description:}

This ingest is still not running, but hardware issues at SGP have been resolved. We will begin shipping spectra data to the ARM Archive soon. The software will be used to generate spectra files that will be shipped directly to the Archive.

\section{Reprocessing Needs}

The next issue of this document will contain information on development needs related to reprocessing.

\section{Future Ingest Development Needs}

In the next few weeks, the underlying libraries used by the ingests will be updated to further standardize the quality check (QC) results and make QC attributes more consistent with recent VAP QC standards.

In future months, the latest generation of database software used by the ingest software will continue to be developed. 